\title{
A new MIF4G domain-containing protein, CTIF, directs nuclear cap-binding protein CBP80/20-dependent translation
}

\author{
Kyoung Mi Kim, ${ }^{1,3}$ Hana Cho, ${ }^{1,3}$ Kobong Choi, ${ }^{2,3}$ Jaedong Kim, ${ }^{2}$ Bong-Woo Kim, ${ }^{1}$ Young-Gyu Ko, ${ }^{1}$ \\ Sung Key Jang, ${ }^{2,5}$ and Yoon Ki Kim ${ }^{1,4}$ \\ ${ }^{1}$ School of Life Sciences and Biotechnology, Korea University, Seoul 136-701, Republic of Korea; ${ }^{2}$ Department of Life Science, \\ Pohang University of Science and Technology, Hyoja Dong, Pohang, Kyungbuk 790-784, Republic of Korea
}

\begin{abstract}
During or right after mRNA export via the nuclear pore complex (NPC) in mammalian cells, mRNAs undergo translation mediated by nuclear cap-binding proteins 80 and 20 (CBP80/20). After CBP80/20-dependent translation, CBP80/20 is replaced by cytoplasmic cap-binding protein eIF4E, which directs steady-state translation. Nonsense-mediated mRNA decay (NMD), one of the best-characterized mRNA surveillance mechanisms, has been shown to occur on CBP80/20-bound mRNAs. However, despite the tight link between CBP80/20-dependent translation and NMD, the underlying molecular mechanism and cellular factors that mediate CBP80/20dependent translation remain obscure. Here, we identify a new MIF4G domain-containing protein, CTIF (CBP80/ 20-dependent translation initiation factor). CTIF interacts directly with CBP80 and is part of the CBP80/20dependent translation initiation complex. Depletion of endogenous CTIF from an in vitro translation system selectively blocks the translation of CBP80-bound mRNAs, while addition of purified CTIF restores it. Accordingly, down-regulation of endogenous CTIF abrogates NMD. Confocal microscopy shows that CTIF is localized to the perinuclear region. Our observations demonstrate the existence of CBP80/20-dependent translation and support the idea that CBP80/20-dependent translation is mechanistically different from steady-state translation through identification of a specific cellular protein, CTIF.
\end{abstract}

[Keywords: CTIF; nonsense-mediated mRNA decay; nuclear cap-binding protein CBP80/20; eukaryotic translation initiation factor $4 \mathrm{G}$; steady-state translation]

Supplemental material is available at http://www.genesdev.org.

Received May 21, 2009; revised version accepted July 13, 2009.

Gene expression in mammalian cells is tightly controlled by a cascade of coordinated cellular processes. Immediately after transcription initiation, pre-mRNA is capped at the $5^{\prime}$ end. The cap structure is recognized by nuclear cap-binding protein 80 and 20 (CBP80/20) (Chang et al. 2007; Isken and Maquat 2007). During transcription, newly synthesized pre-mRNA undergoes splicing, in which introns are removed and a multiprotein complex called the exon junction complex (EJC) is deposited 20-24 nucleotides (nt) upstream of each exon-exon junction (Behm-Ansmant et al. 2007b; Chang et al. 2007; Isken and Maquat 2007; Neu-Yilik and Kulozik 2008). The EJC consists of a core complex including the DEAD-box RNA helicase eIF4AIII, the heterodimer of MAGOH/Y14, Barentsz/MLN51, and other accessory proteins (Behm-

\footnotetext{
${ }^{3}$ These authors contributed equally to this work. Corresponding authors.

${ }^{4}$ E-MAIL yk-kim@korea.ac.kr; FAX 82-2-927-9028.

${ }^{5}$ E-MAIL sungkey@postech.ac.kr; FAX 85-54-279-8009.

Article published online ahead of print. Article and publication date are online at http://www.genesdev.org/cgi/doi/10.1101/gad.1823409.
}

Ansmant et al. 2007b; Chang et al. 2007; Isken and Maquat 2007; Neu-Yilik and Kulozik 2008).

Nonsense-mediated mRNA decay (NMD), which is the best-characterized mRNA surveillance mechanism, recognizes and removes premature termination codon (PTC)-containing mRNAs, thus minimizing the expression of truncated proteins that could be toxic to cellular functions (Behm-Ansmant et al. 2007b; Chang et al. 2007; Isken and Maquat 2007; Neu-Yilik and Kulozik 2008; Rebbapragada and Lykke-Andersen 2009). In general, when a PTC is located $>50-55$ nt upstream of the last exon-exon junction, the mRNA is subject to NMD in mammalian cells. The recognition of PTC is ensured by molecular interaction between the SMG1-Upf1-eRF1eRF3 (SURF) complex and the downstream EJC. The SMG1 complex (SMG1C), which consists of SMG1, SMG8, and SMG9, binds to Upf1 before the formation of SURF. During translation termination on the PTC, the SMG1C-Upf1 complex joins the terminating ribosome on a PTC along with eRF1 and eRF3 to form the SURF complex. Then, the SURF complex associates with the 
EJC downstream from the PTC to form the decayinducing complex (DECID), which triggers the phosphorylation of Upf1 by SMG1 (Yamashita et al. 2005, 2009; Kashima et al. 2006; Chang et al. 2007). Phosphorylated Upf1 may recruit its interacting proteins, SMG5, SMG6, and SMG7 (Unterholzner and Izaurralde 2004; Fukuhara et al. 2005; Huntzinger et al. 2008; Eberle et al. 2009), or proline-rich nuclear receptor coregulatory protein 2 (PNRC2) (Cho et al. 2009) or both to induce mRNA degradation.

NMD is tightly coupled to translation, in that the PTC is recognized by the ribosome. During export of properly matured mRNA via nuclear pore complex (NPC), CBP80/ 20 recruits the ribosome to initiate the CBP80/20dependent translations (CTs) (Ishigaki et al. 2001; Lejeune et al. 2002, 2004; Chiu et al. 2004). At the CT step, the fate of PTC-containing mRNAs can be determined, since NMD occurs only on CBP80/20-bound mRNAs (Ishigaki et al. 2001; Lejeune et al. 2002, 2004; Chiu et al. 2004). During CT, the recruitment of a single ribosome to mRNA may be enough to trigger efficient NMD. However, a significant portion of CBP80 was detected in polysomal fractions in previous studies (Chiu et al. 2004; Sato et al. 2008) and in this study, suggesting that CBP80 may direct a multiple round of translation. These findings raise the important question of whether all CTs are coupled to NMD. For clarity and simplicity, hereafter, CT is defined as translation mediated by CBP80/20.

CBP80/20 is subsequently replaced by the major cytoplasmic cap-binding protein, eukaryotic translation initiation factor (eIF) 4E, which mediates steady-state translation (ST) in the cytoplasm. Many initiation factors involved in ST have been characterized including eIF4E, eIF4GI/II, eIF3, eIF4A, eIF4B, eIF2, poly(A)-binding protein (PABP), and other factors (Pestova et al. 2007). eIF4GI/II serves as a scaffold and binds to eIF4E, eIF4A, eIF3, PABP, and Mnk. Mammalian eIF3, which is composed of at least 13 different polypeptides, binds to the 40S ribosomal subunit. Protein interaction relay (eIF4EeIF4G-eIF3-40S ribosome subunit) is thought to be the key to loading of the 40S ribosome subunit onto the mRNA. eIF4AI/II is an ATP-dependent RNA helicase that is stimulated by eIF4B (Pestova et al. 2007).

Although the molecular mechanism of ST has been studied intensively, the molecular events underlying CT are poorly understood. Based on recent reports, CT differs from ST in the following ways (Ishigaki et al. 2001; Lejeune et al. 2002, 2004; Chiu et al. 2004): First, CT targets newly spliced and CBP80/20-bound mRNAs, whereas ST occurs on eIF4E-bound mRNAs (Ishigaki et al. 2001; Lejeune et al. 2002). Notably, NMD targets CBP80/20-bound mRNA undergoing CT, rather than eIF4E-bound mRNA undergoing ST (Ishigaki et al. 2001; Chiu et al. 2004). Second, CT occurs on mRNAs that harbor EJCs. A ribosome, which is recruited by CBP80/20, removes the EJCs from mRNA during its movement through the mRNA (Ishigaki et al. 2001; Chiu et al. 2004). Consequently, eIF4E-bound mRNA is EJC-free. Third, ST is responsible for the majority of cellular protein synthesis. Fourth, whereas ST allows for rapid re- sponse to changes in physiological conditions or to environmental stresses, CT seems to be resistant to these changes (Maquat and Li 2001; Marin-Vinader et al. 2006; Oh et al. 2007a,b). However, it has been recently reported that the efficiency of CT can be increased upon activation of mammalian target of rapamycin (mTOR)/S6K1 signaling (Ma et al. 2008). Under this condition, 40S ribosomal subunit protein $\mathrm{S} 6$ protein kinase $(\mathrm{S} 6 \mathrm{~K})$ is activated and triggers recruitment of S6K1 Aly/REF-like substrate (SKAR) to the newly synthesized and CBP80-bound mRNAs, activating CT (Ma et al. 2008).

Here we identified a new protein that contains the middle domain of eIF4GI (MIF4G), which we named CT initiation factor (CTIF). We show that CTIF interacts directly with CBP80 and is complexed with eIF3 and eIF4AIII. It also preferentially associates with the EJCbound CT initiation complex. Indeed, in vitro translation experiments show that depletion of endogenous CTIF from the in vitro translation reactions preferentially inhibits the translation of CBP80-bound mRNAs but not eIF4E-bound mRNAs. Addition of purified CTIF restores CT. Accordingly, down-regulation of endogenous CTIF using siRNA abrogates the NMD of PTC-containing $\beta$-globin (Gl) and glutathione peroxidase 1 (GPx1) mRNAs and the NMD of cellular NMD substrates. Consistent with the plausible cellular site for CT (Ishigaki et al. 2001; Lejeune et al. 2002; Chiu et al. 2004), CTIF is highly enriched in the perinuclear region. Our results demonstrate that CTIF is a specific translation initiation factor that is preferentially involved in CT. The regulation of CT, and thereby NMD, by CTIF sheds light on a novel post-transcriptional regulation of gene expression.

\section{Results}

Identification of a new MIF4G domain-containing protein CTIF that interacts with CBP8O

eIF4GI/II has been shown to interact with CBP80 (McKendrick et al. 2001; Lejeune et al. 2004) and to be involved in $\mathrm{CT}$, as demonstrated by inhibition of NMD upon overexpression of polioviral protease 2A or HIV-2 PR, both of which cleave eIF4G (Lejeune et al. 2004). However, the possible cleavage of other factors involved in CT by these proteases was not completely ruled out. In addition, we found that CBP80 did not detectably interact with eIF4GI (Supplemental Fig. 2B). We also found that NMD occurs efficiently during apoptosis where activated caspase 3 cleaves cellular eIF4GI/II (N Oh, KM Kim, H Cho, and YK Kim, unpubl.). All of these findings suggested that another cellular protein plays a role in CT. The possible candidate was hypothesized to interact with CBP80 and to contain the MIF4G domain of eIF4GI (MIF4G), which binds to eIF3, since both CBP80 and eIF3 are involved in NMD (Chiu et al. 2004; Hosoda et al. 2005; Morris et al. 2007).

To search for the possible candidate, we surveyed human EST sequences for MIF4G domain-containing proteins and identified a new protein, which we called the CTIF. CTIF consists of 598 amino acids, sharing $23 \%$ 
identity and $46 \%$ similarity with the MIF4G domain (Fig. 1A; Supplemental Fig. 1A); this domain of eIF4GI interacts with eIF3 and the RNA helicases eIF4AI and eIF4AII (Hinnebusch 2006; Pestova et al. 2007). CTIF was expressed at different levels in all mouse tissues and human cell lines tested (Supplemental Fig. 1B,C).

Based on the sequence similarity between CTIF and the MIF4G domain, we assessed the possible interaction of CTIF with translation initiation factors that have been shown to interact with the MIF4G domain of eIF4GI. First, CBP80 and eIF3, but not eIF4E and eIF4GI, detectably coimmunopurified with Flag-tagged CTIF that was immunoprecipitated from Cos- 7 cells using $\alpha$-Flag antibody. These proteins were complexed with Flag-CTIF in a manner that was resistant to the addition of RNase A prior to immunopurification, suggesting that the interactions between CTIF and coimmunopurified proteins CBP80 and eIF3 are stable in the absence of RNA. The efficiency of RNase A treatment was demonstrated by the disappearance of endogenous GAPDH mRNA in samples that were purified before immunopurification (Fig. 1B, bottom). The cellular protein $\beta$-actin, which served as a negative control, did not copurify with Flag-CTIF. The preferential interaction was corroborated by immunopurification of endogenous CTIF using $\alpha$-CTIF antibody (Supplemental Fig. 2A). Endogenous CBP80, eIF3b, and NMD factor Upf3X copurified with endogenous CTIF that was immunopurified from HeLa cells using $\alpha$-CTIF antibody in an RNase A-resistant manner (Supplemental Fig. 2A). On the other hand, endogenous eIF4E and eIF4GI did not copurify with endogenous CTIF (Supplemental Fig. 2A), which is consistent with the results in Figure 1B.

Second, endogenous CTIF, but not endogenous eIF4GI or eIF4E, preferentially copurified with Myc-tagged CBP80 that was immunopurified from Cos-7 cells using $\alpha$-Myc antibody (Supplemental Fig. 2B). On the other hand, endogenous eIF4GI, but not endogenous CTIF or CBP80, coimmunopurified with endogenous eIF4E that
A

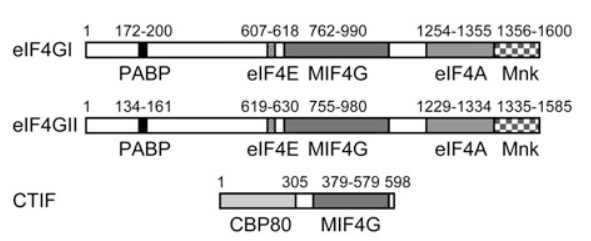

C

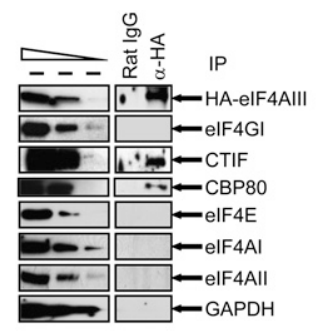

D

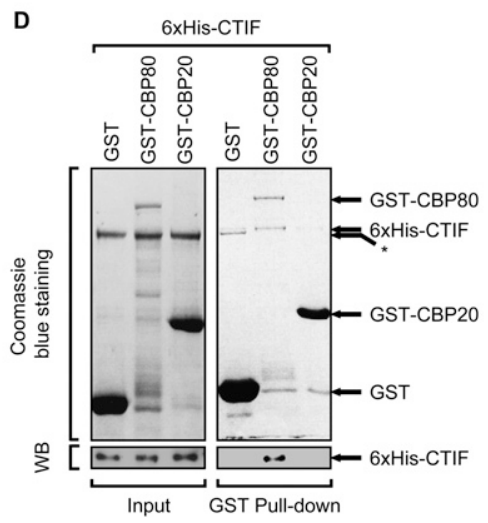

\section{B}

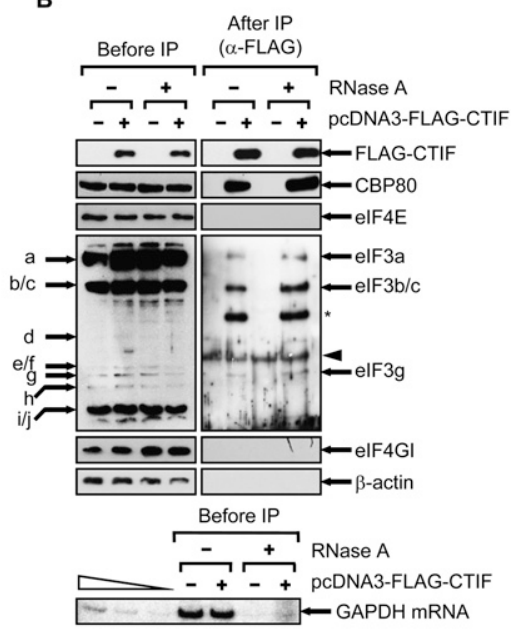

E

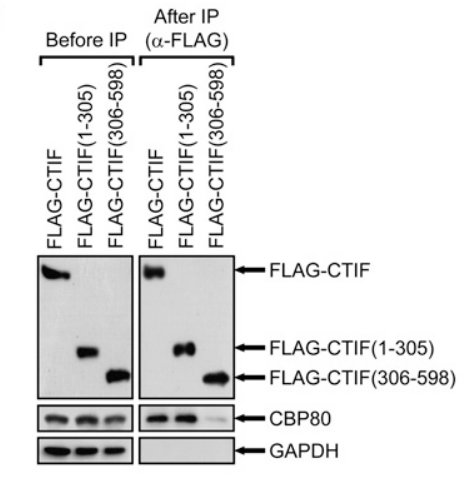

Figure 1. CTIF interacts with CBP80. (A) Alignments of eIF4GI, eIF4GII, and CTIF proteins. The MIF4G domain and the binding sites for CBP80, PABP, eIF4E, eIF4A, and Mnk are indicated. The numbers above indicate the amino acid positions. (B) Immunoprecipitation of Flag-CTIF. (Top) Extracts of Cos-7 cells $\left(4 \times 10^{7}\right)$ that were or were not transiently transfected with $15 \mu \mathrm{g}$ of pcDNA3-Flag-CTIF were analyzed by Western blotting to detect the indicated proteins either before or after immunoprecipitation using $\alpha$-Flag antibody. $\beta$-Actin served as a negative control. Asterisk and arrowhead indicate an undefined nonspecific protein and the heavy chain of $\operatorname{IgG}$, respectively. (Bottom) GAPDH mRNA was analyzed using RT-PCR to demonstrate that the RNase A digestion was complete. Additional details for immunoprecipitation are provided in the Supplemental Material. $(C)$ Immunoprecipitation of HA-eIF4AIII. As in Figure 1B, except that extracts of cells transiently transfected with $10 \mu \mathrm{g}$ of pcDNA3-HAeIF4AIII were analyzed before or after immunoprecipitation using $\alpha$-HA antibody or normal rat serum (rat IgG), as a control for nonspecific immunoprecipitation. GAPDH served as a negative control. The three leftmost lanes, in which threefold serial dilutions of cellular proteins were analyzed, demonstrate that the conditions used for Western blotting were semiquantitative. $(D)$ GST pull-down assays with purified proteins. Recombinant proteins GST, GSTCBP20, GST-CBP80, and 6xHis-CTIF were purified from E. coli. The details for protein purification are provided in the Materials and Methods. GST or GST-fused recombinant protein $(3 \mu \mathrm{g})$ was mixed with purified 6xHis-CTIF $(2 \mu \mathrm{g})$. The mixtures were analyzed by Coomassie blue staining (top) and Western blotting using $\alpha$-CTIF antibody (bottom) either before or after pull-down assays using GST resin. Asterisk indicates a contaminant in the purified GST protein (see Supplemental Fig. 3). Additional details are provided in Materials and Methods. (E) Immunoprecipitation of Flag-CTIF deletions. As in Figure 1B, except that extracts of Cos-7 cells transiently transfected with $15 \mu \mathrm{g}$ of pcDNA3-Flag-CTIF, pcDNA3-Flag-CTIF(1-305), or pcDNA3-Flag-CTIF(306-598) were analyzed before or after immunoprecipitation using $\alpha$-Flag antibody. GAPDH served as a negative control. Each panel of results is representative of at least three independently performed experiments. 
was immunopurified from Cos-7 cells using $\alpha$-eIF4E antibody (Supplemental Fig. 2C).

Third, endogenous CTIF and CBP80 were detected in immunopurification of HA-tagged eIF4AIII using $\alpha$-HA antibody (Fig. 1C). On the other hand, endogenous eIF4GI, eIF4E, eIF4AI, and eIF4AII, all of which are components of the ST initiation complex, did not detectably coimmunopurify with HA-eIF4AIII.

Fourth, GST-tagged CBP80 purified from Escherichia coli specifically interacted with $6 x$ His-tagged CTIF purified from E. coli (Fig. 1D), as shown by GST pull-down assays followed by either Coomassie Blue staining (Fig. $1 \mathrm{D}$, top) or by Western blotting using $\alpha$-CTIF antibody (Fig. 1D, bottom). Notably, GST-CBP20 and GST alone purified from E. coli failed to interact with $6 x$ His-CTIF. Each protein purified from E. coli was shown by Coomassie blue staining (Supplemental Fig. 3). All of these results suggest that CTIF interacts directly with CBP80 and is complexed with CBP80, eIF3, and EJC components. These binding partners for CTIF suggest that CTIF could be involved in CT and therefore NMD.

To determine which region of CTIF interacts with CBP80, two deletion constructs were generated: FlagCTIF(1-305) and Flag-CTIF(306-598). Immunopurification results showed that endogenous CBP80 was enriched in immunopurifications of Flag-CTIF and Flag-CTIF(1305), but not of Flag-CTIF(306-598). These results suggest that the N-terminal half of CTIF was essential for its interaction with CBP80.

Several reports have shown that CBP80 associates with newly synthesized pre-mRNA as well as EJC-bound mRNA, and thus with the CT initiation complex, which is a product of pre-mRNA and a precursor to eIF4E-bound mRNA (Ishigaki et al. 2001; Lejeune et al. 2002; Chiu et al. 2004). Considering the direct interaction between CTIF and CBP80, CTIF is likely to associate with the newly synthesized pre-mRNA. To address this question, we further characterized mRNP complex containing CTIF.

Flag-CTIF associated with intron-containing premRNA and spliced mRNA (Supplemental Fig. 4). This was evident from analysis of semiquantitative RT-PCR to amplify Gl pre-mRNA, Gl mRNA, and MUP mRNA that coimmunopurified with transiently expressed Flag, Flag-CBP80, Flag-eIF4E, or Flag-CTIF in Cos-7 cells (Supplemental Fig. 4). Semiquantitative RT-PCR results revealed that, whereas Flag-CBP80 associated with Gl premRNA, Gl mRNA, and MUP mRNA, Flag-eIF4E preferentially associated with Gl mRNA and MUP mRNA (Supplemental Fig. 4, bottom). Notably, Flag-CTIF associated with Gl pre-mRNA, Gl mRNA, and MUP mRNA (Supplemental Fig. 4, bottom), consistent with the interaction between CTIF and CBP80 (Fig. 1). The specificity of immunopurification was demonstrated by Western blotting of Flag-CBP80, Flag-eIF4E, and Flag-CTIF before and after immunopurification (Supplemental Fig. 4, top). All these results provide strong evidence that CTIF associates with newly synthesized, CBP80-bound and EJC-bound mRNAs, and thus could be a component of the CT initiation complex.

\section{CTIF is a component of the CT initiation complex}

Although our data showed that CTIF interacts with CBP80, eIF3, and EJC components and associates with newly synthesized EJC-containing mRNAs (Fig. 1; Supplemental Figs. 2, 4), when or where these interactions occur remains obscure. To address this question, we first determined whether CTIF is in complex with the functional form of the CT initiation complex (Fig. 2A,B).

Green fluorescent protein (GFP)-tagged CTIF associates with the CT initiation complex, but not with the ST initiation complex (Fig. 2A,B). This was evident by polysome fractionation of extracts of HEK 293T cells transiently expressing GFP-CTIF and either Flag-CBP80 or Flag-eIF4E (Fig. 2A,B, top), followed by immunopurifications using $\alpha$-Flag antibody (Fig. 2A,B, bottom). Upon polysome fractionation, eIF4GI was mainly detected in subpolysome fractions, while Flag-CBP80, Flag-eIF4E, GFP-CTIF, and eIF3b were detected in most fractions before immunopurification (Fig. 2A,B, top). Polysome distributions of CTIF were further confirmed by treatment with puromycin, which dissociates and collapses the polysome into 80S peak, indicating that CTIF truly associates with polysomes (Fig. 2C,D).

Next, the CT complex was distinguished from the ST complex by immunopurification using $\alpha$-Flag antibody. In the immunopurification of Flag-CBP80, a small amount of co-immunopurified eIF4GI was detected in the 40S fraction, whereas GFP-CTIF was highly enriched in disome and subpolysome fractions (Fig. 2A, bottom). In the immunopurification of Flag-eIF4E, eIF4GI was strongly detected in the subpolysome fractions (Fig. 2B, bottom). On the other hand, a very small amount of GFP-CTIF was detected in the $40 \mathrm{~S}$ fraction. eIF3b was also detected in the subpolysome fractions in both immunopurifications (Fig. 2A,B, bottom). All of these results provide strong evidence that CTIF associates preferentially with the CT initiation complex, whereas eIF4GI associates preferentially with the ST initiation complex.

\section{CTIF stimulates the CT in vivo}

We next asked if CTIF affects CT in vivo. To this end, endogenous CTIF and eIF4GI/II were down-regulated using specific siRNAs. Total cell extracts were then analyzed by either polysome fractionation (Fig. 3A-D) or metabolic labeling (Fig. 3E-G).

Polysome fractionations of extracts of HEK293FT cells transfected with CTIF siRNA, eIF4GI/II siRNA, or nonspecific control siRNA revealed that a significant portion of endogenous eIF4E was shifted from polysome or 80S- to 40S-containing fractions upon the down-regulation of eIF4GI/II but not of CTIF (Fig. 3B-D). Notably, FlagCBP80 was significantly shifted to 40S-containing fractions upon the down-regulation of CTIF but not of eIF4GI/II (Fig. 3B,C). Specific down-regulations of endogenous proteins by siRNAs were confirmed by Western blotting (Fig. 3A).

In addition, down-regulation of eIF4GI/II inhibited ST by 2.5-fold, whereas down-regulation of CTIF had no significant effect on ST. This was demonstrated by 


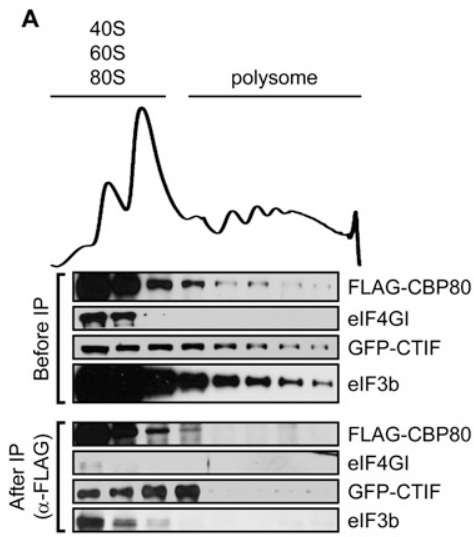

C

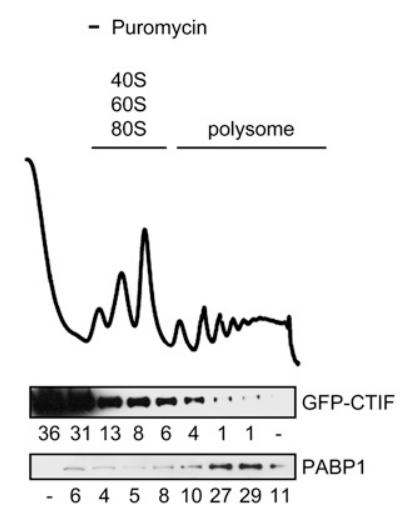

B

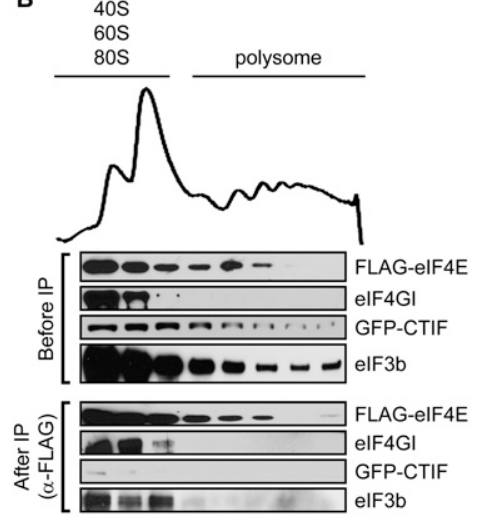

D

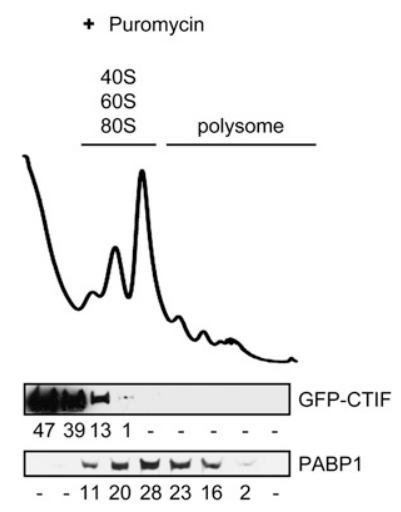

Figure 2. CTIF truly associates with polysomes and is a component of the CT initiation complex. $(A, B)$ Polysomes were fractionated according to size from extracts of HEK293T cells transiently transfected with $5 \mu \mathrm{g}$ of GFP-CTIF and $10 \mu \mathrm{g}$ of either Flag-CBP80 $(A$, top) or Flag-eIF4E $(B, t o p)$. The CT initiation complex in each polysome fraction was separated from the ST initiation complex by immunoprecipitation of Flag-CBP80 ( $A$, bottom) or Flag-eIF4E ( $B$, bottom) using $\alpha$-Flag antibody. Immunopurified proteins were analyzed either before (top) or after (bottom) immunoprecipitation by Western blotting using the indicated antibodies. Each panel of results is representative of at least three independently performed experiments. $(C, D)$ As in Figure 2, A and B, except that cells were transiently transfected with $10 \mu \mathrm{g}$ of GFP-CTIF and polysomes were fractionated according to size from extracts pretreated without $(C)$ or with $(D) 100 \mu \mathrm{g} / \mathrm{mL}$ of puromycin. Fractionated proteins were analyzed by Western blotting using $\alpha$-GFP antibody and $\alpha$-PABP1 antibody. Each panel of results is representative of at least two independently performed experiments. metabolic labeling with $\left[{ }^{35} \mathrm{~S}\right]$-methionine and subsequent autoradiography of cells depleted of endogenous CTIF or eIF4GI/II (Fig. 3F,G). Specific down-regulations of endogenous proteins by siRNAs were confirmed by Western blotting (Fig. 3E). All results suggest that CTIF and eIF4GI/II direct CT and ST, respectively.

\section{Depletion of endogenous CTIF and add-back of purified CTIF inhibits and restores the translation of CBP80-bound mRNAs, respectively}

The above results led us to test whether depletion of endogenous CTIF and add-back of recombinant CTIF could selectively inhibit and restore the CT in vitro, respectively. To test this possibility, we first needed to purify CBP80-bound and EJC-containing mRNAs, since our data showed that CTIF interacted with EJC components in addition to CBP80 (Fig. 1; Supplemental Figs. 2, 4). To this end, Cos-7 cells were transiently transfected with two plasmids: (1) the reporter plasmid pRL-CMV that encodes Renilla luciferase (RLuc) cDNA and a chimeric intron upstream of RLuc cDNA, and (2) a plasmid that expresses Flag-CBP80, Flag-eIF4E, or Flag tag only (Supplemental Fig. 5). Two days after transfection, ribonucleoprotein (RNP) complex containing either FlagCBP80 or Flag-eIF4E was immunopurified by immunopurification using $\alpha$-Flag antibody and then eluted from the resin using Flag peptides. The 5'-cap structures of RLuc mRNAs in the eluted RNP complexes were thus bound by either Flag-CBP80 or Flag-eIF4E. The specificity of immuopurification was demonstrated by Western blotting using $\alpha$-Flag antibody (Supplemental Fig. 5A), semiquantitative RT-PCR (Supplemental Fig. 5B), and quantitative real-time PCR (Supplemental Fig. 5C). Western blotting results revealed that the cellular protein $\beta$-actin, which served as a negative control, was not detected in the eluted RNP complexes after immunopurification of Flag-CBP80 or Flag-eIF4E (Supplemental Fig. 5A). In addition, endogenous CBP80 and eIF4E did not detectably coimmunopurify with the eluted Flag-eIF4Econtaining RNP complex and Flag-CBP80-containing RNP complex, respectively, suggesting that eIF4E and its bound RLuc mRNA are absent from immunopurification of Flag-CBP80, and CBP80 and its bound RLuc mRNA are absent from immunopurification of FlageIF4E. In addition, semiquantitative RT-PCR and realtime PCR revealed that comparable amounts of RLuc mRNAs coimmunopurified with Flag-CBP80 and FlageIF4E (Supplemental Fig. 5B,C). Furthermore, although strong RLuc activity was detected in cell extracts before immunopurification, only the basal level of RLuc activity was detected in the eluted RNP complex after immunopurification of Flag-CBP80 or Flag-eIF4E (Supplemental Fig. 5D), which demonstrated that RLuc protein is absent from the RNP complex eluted using Flag peptides after immunopurification.

Next, the eluted RNP complex was added to in vitro translation reactions prepared from the cytoplasmic 
Figure 3. CTIF preferentially directs $\mathrm{CT}$ in vivo. $(A-D)$ Polysomes were fractionated according to size from extracts of HEK293FT cells transiently transfected with nonspecific control siRNA $(B)$, CTIF siRNA $(C)$, or eIF4GI/II siRNA $(D)$. (A) Western blotting of endogenous eIF4GI, eIF4GII, and CTIF. $(B-D)$ Western blotting of Flag-CBP80 and eIF4E in polysome fractions. The numbers below each panel denote quantitative representation of Flag-CBP80 or eIF4E distribution in polysome fractions. Relative level of Flag-CBP80 or eIF4E in each fraction was calculated as a percentage of the total. $(E-G)$ HEK293FT cells were transiently transfected with CTIF siRNA, eIF4GI/II siRNA, or nonspecific control siRNA. Three days after transfection, newly synthesized proteins were monitored by metabolic labeling of proteins with $\left[{ }^{35} S\right]$-methionine. $(E)$ Western blotting of eIF4GI, eIF4GII, and CTIF. $(F)\left[{ }^{35} \mathrm{~S}\right]-$ Met-labeled total cell extracts were subjected to $10 \%$ SDS-PAGE and stained with Coomassie brilliant blue (left) or subjected to autoradiography $\left(\right.$ right). $(G)$ Aliquots of each $\left[{ }^{35} \mathrm{~S}\right]$-Met-labeled totalcell extract were precipitated by $10 \%$ TCA, and the radioactivities in the precipitated proteins were measured by a liquid scintillation counter. The mean counts per minute (CPM) obtained from cells transfected with control siRNA was set to 1. Each panel of results is representative of at least three independently performed siRNA transfections, metabolic labeling with $\left[{ }^{35} \mathrm{~S}\right]-\mathrm{Met}$, TCA precipitations, and measurements of radioactivity.
A

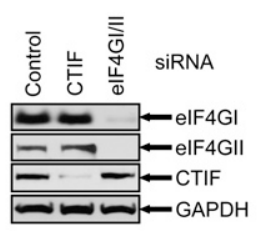

B
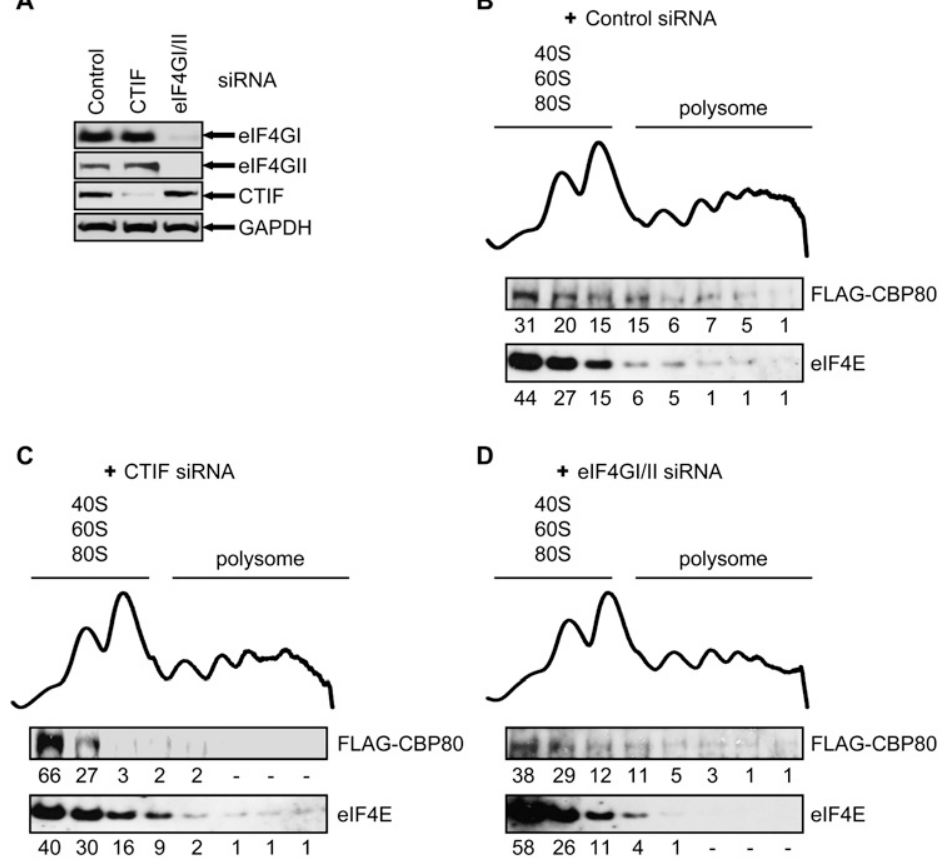

D

+ elF4GI/II SiRNA $40 \mathrm{~S}$ 605
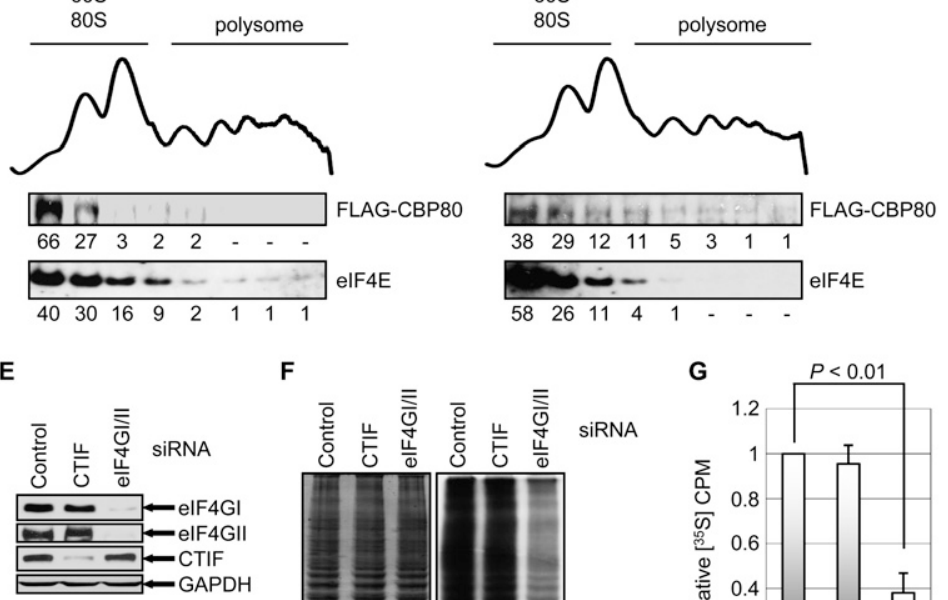

$\mathbf{F}$

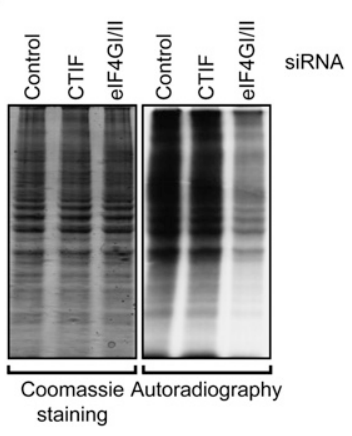

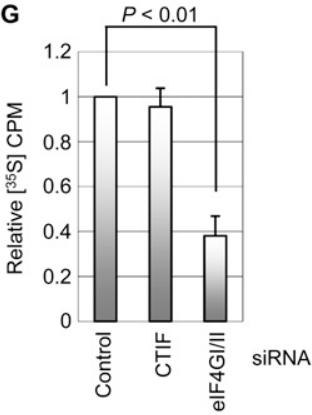

extracts of HEK293FT cells depleted of endogenous CTIF or eIF4GI/II using specific siRNAs (Fig. 4). Specific downregulations of CTIF, eIF4GI, and eIF4GII were confirmed by Western blotting (Fig. 4A). To minimize the possible exchange of CBP80/20 to eIF4E during in vitro translation, in vitro translation reactions were performed for just $15 \mathrm{~min}$ at $30^{\circ} \mathrm{C}$ as described in the Materials and Methods. In vitro translation results revealed that translation of Flag-CBP80-bound RLuc mRNA was significantly inhibited (approximately twofold) by depletion of CTIF, but not eIF4GI/II (Fig. 4B, top). On the other hand, translation of Flag-eIF4E-bound RLuc mRNA was significantly inhibited (approximately twofold) by depletion of eIF4GI/II but not CTIF (Fig. 4C, top). Furthermore, addback of purified $6 x$ His-CTIF to CTIF-depleted extracts restored the translation of CBP80-bound RLuc mRNA (Fig. 4B, top), whereas translation of Flag-eIF4E-bound RLuc mRNA was not affected by depletion of CTIF or addition of purified 6xHis-CTIF (Fig. 4C, top). Notably, depletion of CTIF or addition of purified 6xHis-CTIF had no significant effect on the stabilities of immunopurified RLuc mRNAs, which was demonstrated by semiquanti- tative RT-PCR (Fig. 4B,C, middle) and quantitative realtime PCR (Fig. 4B,C, bottom). All results from immunopurification-coupled in vitro translation experiments strongly indicate that CTIF selectively directs CT.

\section{Down-regulation of endogenous CTIF abolishes NMD of PTC-containing Gl and GPX1 $m R N A$ and NMD of cellular NMD substrates}

NMD occurs as a consequence of CT when mRNAs contain PTCs (Ishigaki et al. 2001; Chiu et al. 2004). We therefore analyzed the abundance of Gl and GPx1 mRNAs harboring PTC in HeLa cells depleted of endogenous CTIF or a key NMD factor Upf1 (Sun et al. 1998; Lykke-Andersen et al. 2000; Mendell et al. 2002). HeLa cells were transfected with Upf1 siRNA, CTIF siRNA, or a nonspecific "control" siRNA. Two days later, cells were transiently retransfected with three plasmids: (1) the test plasmid pmCMV-Gl (Zhang et al. 1998) that is either nonsense-free (Norm) or contains a PTC at the 39th amino acid position (39Ter) of the globin (Gl) gene; (2) the test plasmid pmCMV-GPx1 (Moriarty et al. 1998), 
A

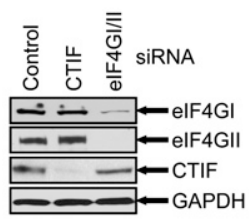

B

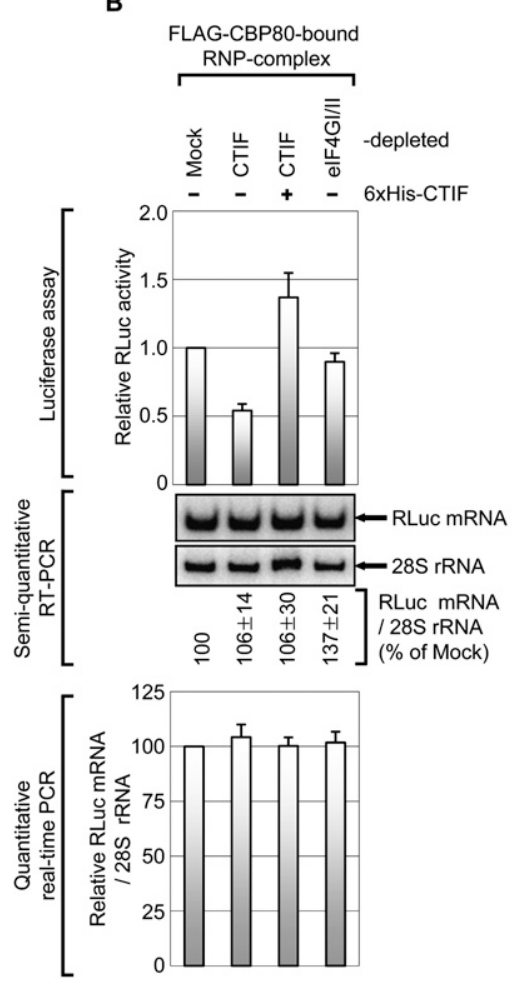

c
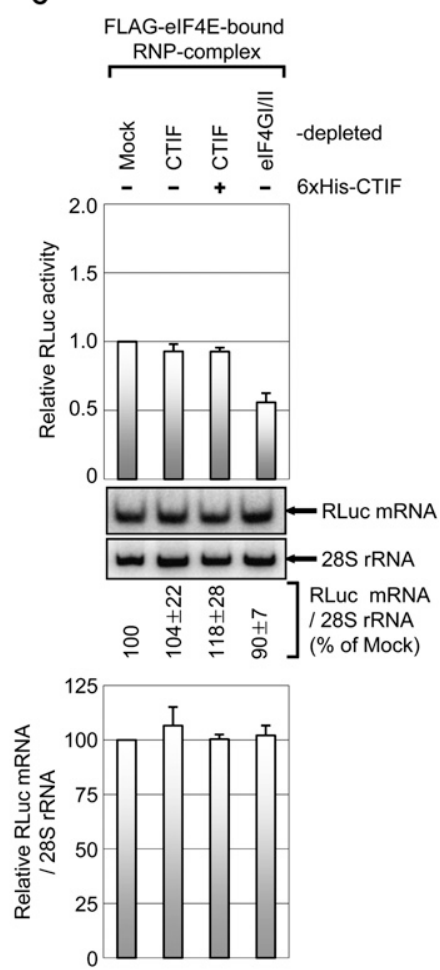

Figure 4. Depletion of CTIF and add-back of purified CTIF inhibits and restores the CT, respectively. $(A)$ The cytoplasmic cell extracts for in vitro translation were prepared from HEK293FT cells depleted of endogenous CTIF or eIF4GI/II by siRNA. The prepared cell extracts were analyzed by Western blotting using the indicated antibodies. $(B, C$, top $)$ In vitro translation reactions of Flag-CBP80-bound $(B)$ or Flag-eIF4E-bound $(C)$ RNP complex that was immunopurified using $\alpha$-Flag antibody from Cos-7 cells transiently transfected with $10 \mu \mathrm{g}$ of a reporter plasmid pRL-CMV expressing RLuc and 10 $\mu \mathrm{g}$ of pcDNA3-Flag, pcDNA3-Flag-CBP80, or pcDNA3Flag-eIF4E. Additional details for the RNP complex are provided in the Materials and Methods (see also Supplemental Fig. 5). In vitro translation reactions were performed in the absence or presence of purified 6xHisCTIF. After in vitro translation, the levels of in vitrosynthesized RLuc protein were monitored by luciferase assay. The value of RLuc activity obtained from in vitro translation reaction of eluted mRNP complex in the mock-depleted extracts was defined as 1 . (The absolute RLuc values of these samples in $B$ and $C$ were $\sim 3000$ and 10,000, respectively.) The columns and bars in each panel represent the means and standard deviations of results obtained from three independently performed immunoprecipitations, in vitro translations, and luciferase assays. (B,C, middle) After in vitro translation, total RNAs were purified and the level of RLuc mRNA was monitored by semiquantitative RT-PCR. Each RLuc mRNA was normalized to 28S rRNA. The normalized level of RLuc mRNA in the mock-depleted extract was defined as 100 . (B,C, bottom) The same samples obtained from $B$, middle, and $C$, middle, were analyzed by quantitative real-time PCR. either Norm or 46Ter; and (3) the reference plasmid phCMV-MUP (Belgrader et al. 1994) to control for variations in the efficiencies of transfection and RNA recovery (Fig. 5).

Western blotting results indicate that the levels of endogenous Upf1 and CTIF were down-regulated to $2 \%$ and $4 \%$ of normal, respectively, where normal is defined as the level in the presence of the nonspecific control siRNA (Fig. 5A). Semiquantitative RT-PCR showed that down-regulation of Upf1 or CTIF abrogated the NMD of PTC-containing Gl mRNA by 3.5-fold or 2.6-fold, respectively (Fig. 5B), and the NMD of PTC-containing GPx1 mRNA by fourfold or 4.3-fold, respectively (Fig. 5C). Comparable results were obtained using a different CTIF siRNA that targets a distinct sequence of CTIF mRNA (Supplemental Fig. 6). In addition, the quantitative real-time PCR results were similar to those obtained by semiquantitative RT-PCR, which demonstrates that our semiquantitative RT-PCR is sufficiently quantitative (Supplemental Fig. 6).

A subset of cellular transcripts have been shown to be targeted for NMD, making NMD one of mechanisms for post-transcriptional regulation of gene expression (Mendell et al. 2004; Rehwinkel et al. 2006; Wittmann et al. 2006; Viegas et al. 2007). To further determine the role of CTIF in CT and thereby NMD, endogenous CTIF was down-regulated using siRNA and the half-lives of the endogenous NMD substrates, COMM domain containing 7 (COMMD7) mRNA and isoleucine-tRNA synthetase (IARS) mRNA, were analyzed (Fig. 5). Recently, we identified these two transcripts as cellular NMD substrates, and each contains an upstream ORF (Cho et al. 2009). Down-regulation of Upf1 or CTIF increased the half-lives of both COMMD7 mRNA and IARS mRNA (Fig. 5D-F). All of these results support our idea that CTIF plays a pivotal role in CT and, consequently, in NMD.

\section{CTIF is localized to the perinuclear region}

Next, we determined the intracellular distribution of CTIF by immunostaining HeLa cells (Fig. 6). Immunostaining of HeLa cells (Fig. 6) or Cos-7 cells (Supplemental Fig. 7) revealed that Flag-CTIF, Myc-CTIF, and endogenous CTIF were mainly localized to the perinuclear region; a minor portion was detected in nuclei and cytoplasm. On the other hand, most endogenous eIF4GI was dispersed throughout the cytoplasm (Fig. 6A; Supplemental Fig. 7A). Furthermore, distribution of Lamin A/C, which is a component of the fibrous nuclear lamina on the nucleoplasmic side of the inner nuclear membrane 
Figure 5. Down-regulation of CTIF abrogates NMD of globin (Gl) mRNA and GPxl mRNA harboring PTC and NMD of cellular NMD substrates. $(A-C)$ HeLa cells were transiently transfected with $100 \mathrm{nM}$ Upf1 siRNA, CTIF siRNA, or nonspecific control siRNA. Two days later, cells were retransfected with $0.05 \mu \mathrm{g}$ of pmCMV-Gl and $0.05 \mu \mathrm{g}$ of pmCMVGPx1 test plasmids, either PTC-free (Norm) or PTCcontaining (Ter), and $0.1 \mu \mathrm{g}$ of the phCMV-MUP reference plasmid. After an additional day, protein and RNA were purified. (A) Western blotting of Upf1 or CTIF, where the level of $\beta$-actin served to control for variations in protein loading. $(B, C) \mathrm{RT}-\mathrm{PCR}$ of Gl mRNA $(B)$ or GPx1 mRNA $(C)$, which was normalized to the level of MUP mRNA. Normalized levels of Norm mRNA in the presence of each siRNA were defined as $100 \%$. The means and standard deviations of results obtained from three independently performed transfections and semiquantitative RT-PCRs are presented below the panels. RT-PCR results obtained in at least three independently performed experiments varied by $<11 \%$. $(D-F)$ HeLa cells were transiently transfected with the indicated siRNA. Two days later, cells were treated with 100 $\mu \mathrm{g} / \mathrm{mL}$ of 5,6-dichloro-1- $\beta$-D-ribofuranosylbenzimidazole (DRB) to block transcription. Cells were harvested and total RNAs were purified at the indicated time points. $(D)$ Semiquantitative RT-PCRs of COMMD7, IARS, and GAPDH mRNAs. GAPDH mRNA was used to control for variations in RNA purification and RT-PCR. $(E, F)$ The intensity of each band was quantitated, and the levels of COMMD7 mRNA $(E)$ and IARS mRNA $(F)$, which were normalized to GAPDH mRNA, were plotted as a function of time after DRB treatment. Normalized level of COMMD7 mRNA $(E)$ or IARS mRNA $(F)$ at $0 \mathrm{~h}$ was defined as $100 \%$.

(Mattout et al. 2006), overlapped the localization of FlagCTIF (Fig. 6B,C) or endogenous CTIF (Fig. 6D). An enlarged view shows that Lamin $\mathrm{A} / \mathrm{C}$ was surrounded by Flag-CTIF (Fig. 6C). All of these results indicate that CTIF is a perinuclear protein.

Myc-CBP80 was highly enriched in nucleus (Fig. 6E). $\mathrm{CT}$ is proposed to occur during mRNA export through NPC from nucleus to cytoplasm (Ishigaki et al. 2001; Maquat 2005; Isken and Maquat 2007). Thus, our observations of the nuclear localization of CBP80 and the perinuclear distribution of CTIF strengthen the idea that mRNPs in transit through the NPC recruit CTIF via interaction between CBP80 and CTIF to initiate CT.

\section{Discussion}

Here we identify a new MIF4G domain-containing protein CTIF. We demonstrate that CT preferentially uses CTIF, rather than eIF4GI, to recruit the 40S small subunit of the ribosome via eIF3. Based on our results, we propose a model in which CBP80/20-CTIF-eIF3 interactions are critical for recruitment of the $40 \mathrm{~S}$ ribosome for $\mathrm{CT}$, analogous to the eIF4E-eIF4GI/II-eIF3 interactions that are essential for 40S recruitment into mRNA for ST (Fig. 7). Once the nascent pre-mRNA is capped immediately after or during transcription initiation in the nucleus, the heterodimer of CBP80/20 binds cotranscriptionally to the cap structure. It has been proposed that CT occurs during mRNA export from nucleus to cytoplasm through the
NPC (Ishigaki et al. 2001; Chang et al. 2007; Isken and Maquat 2007). Given that (1) CTIF interacts with CBP80 and EJC components (Fig. 1; Supplemental Fig. 2), (2) CTIF associates with EJC-bound mRNA (Supplemental Fig. 4), and (3) a major fraction of CTIF is localized to the perinuclear region (Fig. 6; Supplemental Fig. 7), it is plausible that CTIF can be loaded onto CBP80/20-bound mRNP undergoing mRNA export. The loaded CTIF may recruit eIF3 via its MIF4G domain and in turn recruit the 40S ribosome subunit to direct CT (Fig. 7). However, we cannot exclude the less plausible possibilities that CTIF binds to pre-mRNA immediately after CBP80 binding to the cap structure or that it forms a complex with CBP80/ 20 before CBP80/20 recognizes the cap structure, because the minor portion of CTIF is detected in nucleus (Fig. 6; Supplemental Fig. 7) and CTIF associates with premRNAs as well as mRNAs (Supplemental Fig. 4).

Even if our results revealed an undetectable or weak interaction between CBP80 and CTIF (Figs. 1, 2; Supplemental Fig. 2), the possibility of CBP80/20-eIF4GI/IIeIF3 for CT cannot be excluded based on the previously reported interaction between eIF4GI and CBP80 (McKendrick et al. 2001; Lejeune et al. 2004). This discrepancy and preferential interaction between CBP80 and CTIF under our conditions could be due to the intrinsic strong binding affinity between CBP80 and CTIF and/or due to the relatively weak sensitivity of Western blotting under the conditions we used, although overexposure of the film did not reveal an interaction between 

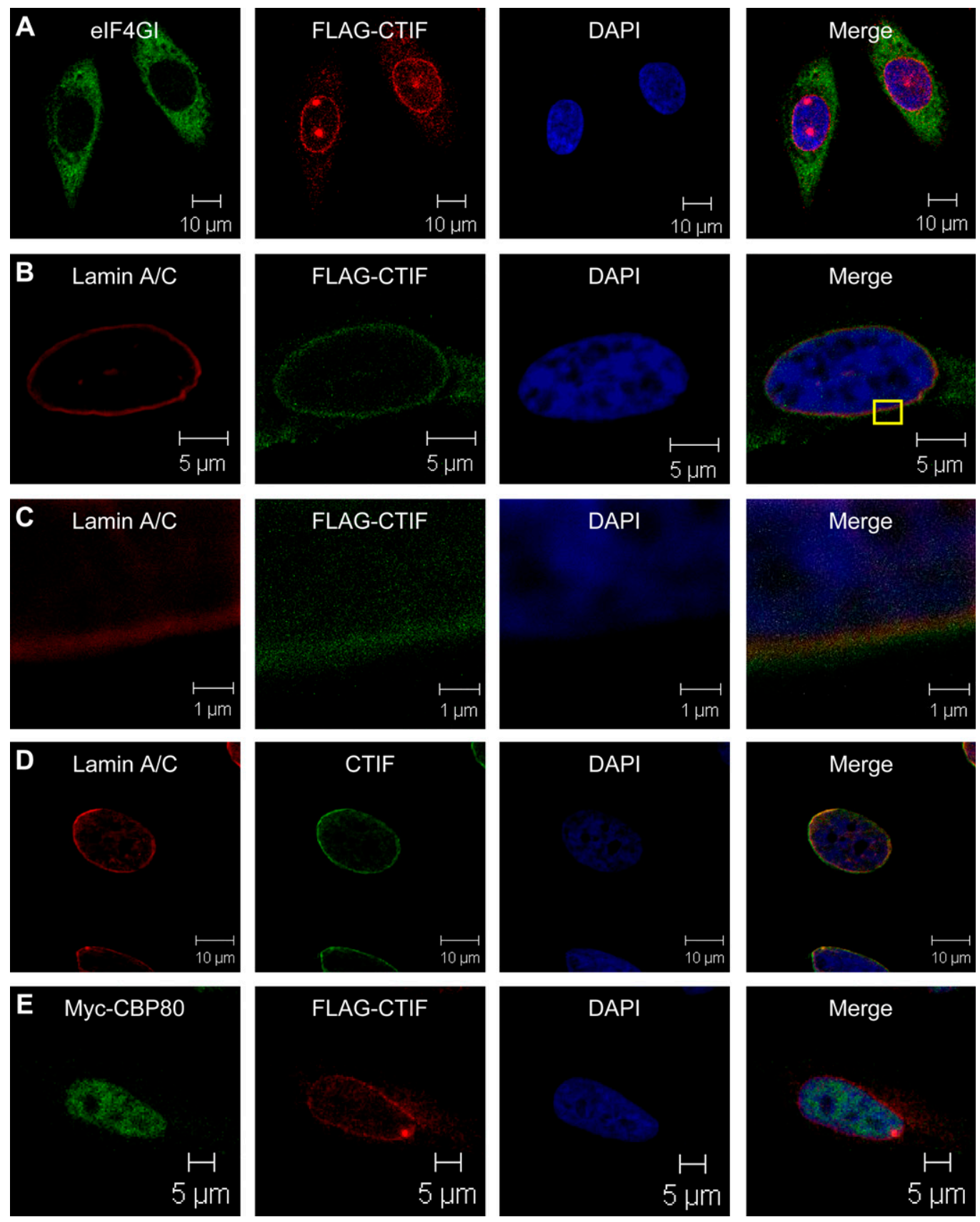

Figure 6. CTIF is localized to the perinuclear region. HeLa cells were transiently transfected with $2 \mu \mathrm{g}$ of indicated plasmids and then stained with specific antibodies. Immunostaining for Flag-CTIF $(A-C, E)$, endogenous CTIF $(D)$, endogenous eIF4GI $(A)$, endogenous Lamin A/C $(B-D)$, or Myc-CBP80 $(E)$ were performed. Enlarged views of boxed region in $B$ are shown in $C$.

Myc-CBP80 and eIF4GI in Supplemental Figure 2B (data not shown).

In support of our findings that suggest the less possible functional relevance between CBP80/20 and eIF4GI, the interaction between nuclear cap-binding complex (CBC) and eIF4G is dispensable for the CT and ST in yeast (Baron-Benhamou et al. 2003). Unlike in yeast, CBP20 and CBP80 have been shown to interact directly with eIF4GI in mammals (Lejeune et al. 2004). Also, it has been shown that NMD is abrogated upon eIF4GI cleavage by HIV-2 PR or poliovirus 2A protease. However, both HIV-2 PR and poliovirus $2 \mathrm{~A}$ protease cleave many cellular proteins including PABP1 (Joachims et al. 1999; Alvarez et al. 2006). Notably, endogenous CTIF in HeLa cells is not cleaved by polioviral infection (data not shown). Therefore, whether the inhibition of NMD by HIV-2 PR or poliovirus 2A protease is due to cleavage of eIF4GI, PABP1, or another factor should be determined, since PABPs in the cytoplasm, for instance, have multiple roles in translation initiation and termination, ribosome 
Figure 7. Model of CT and ST in mammalian cells. (A) CT. The CT initiation complex is composed of CBP80/20, CTIF, EJC /only two EJC components, eIF4AIII and Upf3X, are specified), and probably eIF3. During mRNA export via NPC, CTIF, which is localized to perinuclear region, may be recruited to this complex through its interaction with CBP80 as indicated by an arrow. In turn, CTIF may recruit eIF3 via its MIF4G domain. As in ST initiation, eIF3 may contribute to the loading of $40 \mathrm{~S}$ ribosome subunit onto $5^{\prime}$ end of mRNA. $(B)$ ST. After CT, CBP80/20 is replaced by eIF4E in the cytoplasm. eIF4E interacts with eIF4GI/II. In turn, eIF4GI/II interacts with eIF4AI/II and eIF3. Finally, eIF3 recruits the 40S ribosome subunit. (20) CBP20; (80) CBP80; (AUG) translation initiation codon; (STOP) translation termination codon; (40S) 40S ribosome subunit; (60S) 605 ribosome subunit.

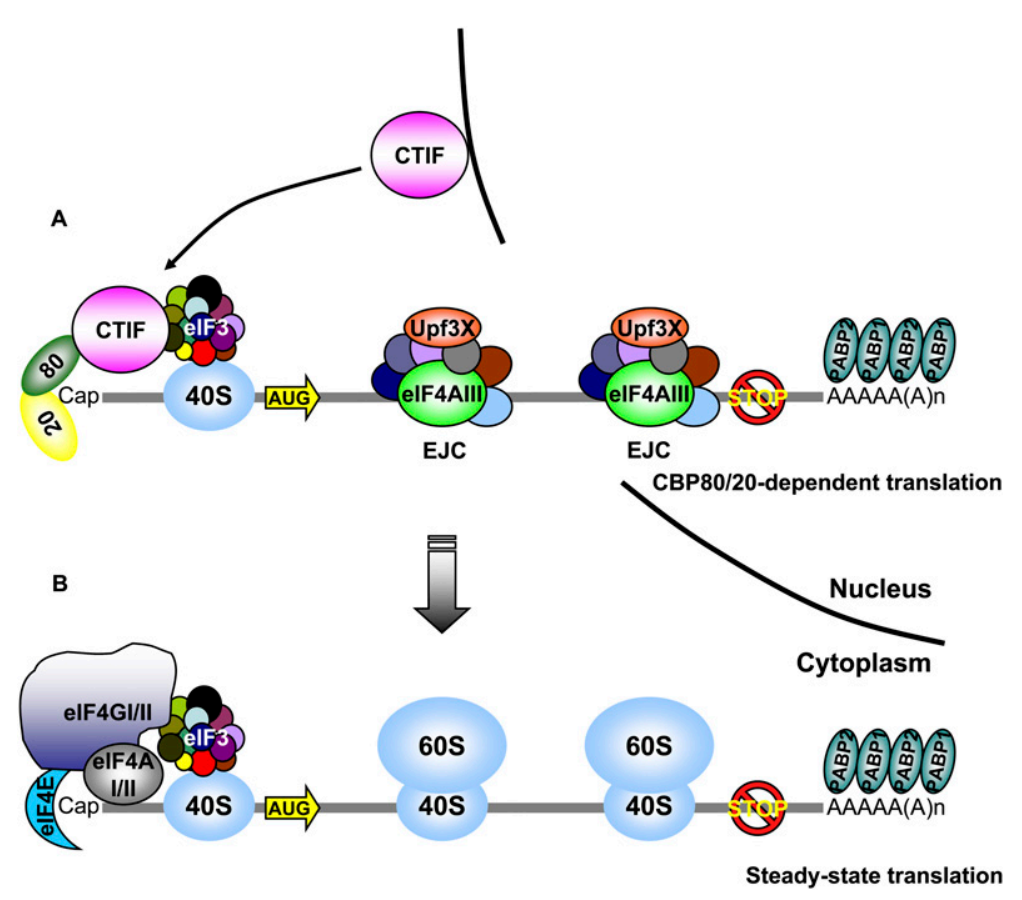

recycling, and mRNA stability (Mangus et al. 2003). Indeed, PABP1 has recently been implicated in NMD (Behm-Ansmant et al. 2007a).

In summary, our observations support that CT is mechanistically different from ST through identification of a specific cellular protein, CTIF, which is preferentially involved in CT. Intriguing questions arise from our findings. Is perinuclear distribution of CTIF essential for $\mathrm{CT}$ ? Is replacement of CBP80 by eIF4E modulated by CTIF? Does EJC communicate with CTIF in order to trigger translation of spliced mRNAs? These questions need to be addressed in future studies.

\section{Materials and methods}

Plasmid constructions

Plasmids were generated as described in the Supplemental Material.

\section{Immunoprecipitations}

Cos-7 cells or HeLa cells were transfected with the indicated plasmids. Two days after transfection, cells were lysed, and total protein and RNA were purified either before or after immunopreciptiation as described previously (Ishigaki et al. 2001; YK Kim et al. 2005; Cho et al. 2009). Additional details for immunoprecipitations are provided in the Supplemental Material.

\section{Western blotting}

Cell extracts or immunopurified proteins were electrophoresed in SDS-polyacrylamide, transferred to Hybond ECL nitrocellulose (Amersham), and probed with specific antibody. The following antibodies were used: Flag (Sigma), HA (Sigma), Myc (Calbiochem), GFP (Santa Cruz Biotechnologies), CBP80 (Li et al. 1999), eIF4E (BD Biosciences), Upf1 and Upf3X (gifts from
L.E. Maquat), eIF3 (Etchison et al. 1982), eIF4AI (Abcam), eIF4AII (Abcam), eIF3b (Santa Cruz Biotechnologies), eIF4GI (WJ Kim et al. 2005), eIF4GII (WJ Kim et al. 2005), PABP1 (Santa Cruz Biotechnologies), $\beta$-actin (Sigma), and GAPDH (Ab Frontier). Antibody against purified CTIF was raised in rabbits.

\section{Recombinant protein purification}

Recombinant proteins GST, GST-CBP20, and GST-CBP80 were expressed in E. coli M15 after transforming cells with plasmids pGEX, pGEX-CBP20, and pGEX-CBP80, respectively. IPTG (final concentration of $0.5 \mathrm{mM}$ ) was added to the medium when the OD $600 \mathrm{~nm}$ value was 0.5 . After additional cultivation for $2 \mathrm{~h}$ at $27^{\circ} \mathrm{C}$, cells were harvested, resuspended in lysis buffer $(20 \mathrm{mM}$ Na-Phosphate at $\mathrm{pH} 7.6,300 \mathrm{mM} \mathrm{NaCl}, 0.5 \mathrm{mM}$ PMSF, $1 \mathrm{mM}$ $\beta$-mercaptoethanol, $10 \%[\mathrm{v} / \mathrm{v}]$ glycerol) and sonicated. GST fusion proteins were allowed to bind to Glutathione Sepharose $4 \mathrm{~B}$ resin (Amersham-Pharmacia Biotech) in lysis buffer for $2 \mathrm{~h}$ at $4^{\circ} \mathrm{C}$. After washing protein-bound resin four times with lysis buffer, proteins were eluted with elution buffer $(50 \mathrm{mM}$ Tris- $\mathrm{HCl}$ at $\mathrm{pH}$ 8.0, $10 \mathrm{mM}$ glutathione).

Recombinant 6xHis-CTIF was expressed in E. coli Rossettagami after transforming cells with plasmid pQE-CTIF. IPTG (final concentration of $0.5 \mathrm{mM}$ ) was added to the medium when the OD $600 \mathrm{~nm}$ value was 0.5 . After additional cultivation at $18^{\circ} \mathrm{C}$ for $24 \mathrm{~h}$, cells were harvested, resuspended in lysis buffer (50 mM Tris- $\mathrm{HCl}$ at $\mathrm{pH} 7.5,500 \mathrm{mM} \mathrm{NaCl}, 0.5 \mathrm{mM}$ PMSF, $1 \mathrm{mM}$ $\beta$-mercaptoethanol, $10 \%$ [v/v] glycerol) and sonicated. The resulting cell extracts were loaded onto a Ni-nitrilotriacetic acidagarose column (Qiagen) equilibrated with lysis buffer containing $10 \mathrm{mM}$ imidazole. The columns were washed with lysis buffer containing $40 \mathrm{mM}$ imidazole, and bound 6xHis-CTIF protein was eluted with $200 \mathrm{mM}$ imidazole.

\section{GST pull-down assays}

GST pull-down assays were performed using recombinant GST, GST-CBP20, GST-CBP80, and 6xHis-CTIF. Following incubation 
of GST fusion proteins (final concentration of $3 \mu \mathrm{g}$ ) and 6xHisCTIF $(2 \mu \mathrm{g})$ in $1 \mathrm{~mL}$ of incubation buffer $(10 \mathrm{mM}$ HEPES at $\mathrm{pH}$ 7.4, $1.5 \mathrm{mM}$ magnesium acetate, $150 \mathrm{mM}$ potassium acetate, 2.5 $\mathrm{mM}$ dithiothreitol [DDT], $0.05 \% \mathrm{NP}-40$ ) for $30 \mathrm{~min}$ at $4^{\circ} \mathrm{C}$, Glutathione Sepharose 4B resin was added to the mixture and incubated for $1 \mathrm{~h}$. After incubation, the resin was washed four times with incubation buffer, and resin-bound proteins were resolved by $10 \%$ SDS-PAGE, followed by Coomassie Blue staining or Western blotting.

\section{Polysome fractionation}

Polysome fractionations were performed as described previously (You et al. 2007). HEK293T cells $(3 \times 150-\mathrm{mm}$ culture dish) transiently expressing GFP-CTIF and either Flag-CBP80 or FlageIF4E were treated with $100 \mu \mathrm{g} / \mathrm{mL}$ cycloheximide (Sigma) for 5 min at $37^{\circ} \mathrm{C}$. Two days after transfection, cells were harvested and washed three times with ice-cold PBS containing $100 \mu \mathrm{g} / \mathrm{mL}$ cycloheximide. The cytoplasmic extracts were prepared as described previously (Rousseau et al. 1996). Then, $1 \mathrm{~mL}$ of cytoplasmic extract was layered onto $10 \mathrm{~mL}$ of $10 \%-50 \%$ sucrose gradient and centrifuged at 40,000 rpm in a Beckman SW-41 Ti rotor for $2 \mathrm{~h}$ at $4^{\circ} \mathrm{C}$. Gradients were fractionated using an ISCO tube piercer (Brandel) and a liquid chromatography system equipped with an absorbance monitor $(254 \mathrm{~nm})$ and fraction collector (Bio-Rad). When indicated, each fraction was immunoprecipitated using $\alpha$-Flag antibody.

When indicated, puromycin $(100 \mu \mathrm{g} / \mathrm{mL})$ was added to the cultures $2 \mathrm{~h}$ prior to harvesting without treatment of cycloheximide.

When indicated, HEK293FT cells were transfected with 100 $\mathrm{nM}$ in vitro-synthesized siRNA (Invitrogen) using Lipofectamine2000 (Invitrogen). Two days after siRNA transfection, cells were retransfected with pcDNA3-Flag-CBP80 plasmid. After two additional days, polysomal fractionations were performed as described above.

\section{Preparation of HEK293FT cell cytoplasmic extract}

HEK293FT cells $\left(\sim 5 \times 10^{8}\right)$ were cultured and harvested. After washing with isotonic buffer $(35 \mathrm{mM}$ HEPES at $\mathrm{pH} 7.5,150 \mathrm{mM}$ $\mathrm{NaCl}, 10 \mathrm{mM}$ glucose), the cell paste was resuspended in $1.5 \mathrm{vol}$ of hypotonic buffer $(10 \mathrm{mM}$ HEPES at $\mathrm{pH} 7.5,10 \mathrm{mM}$ potassium acetate, $1.5 \mathrm{mM}$ magnesium acetate, $2.5 \mathrm{mM}$ DTT) and then Dounce-homogenized. The sample was centrifuged at $30,000 \mathrm{~g}$ for $20 \mathrm{~min}$. The supernatant was dialyzed against buffer $(10 \mathrm{mM}$ HEPES at $\mathrm{pH} 7.5,90 \mathrm{mM}$ potassium acetate, $1.5 \mathrm{mM}$ magnesium acetate, $2.5 \mathrm{mM} \mathrm{DTT}$ ), and treated with micrococcal nuclease to remove endogenous nucleic acids.

\section{Metabolic labeling}

HEK293FT cells (one -six-well culture dish) were transfected with $100 \mathrm{nM}$ in vitro-synthesized siRNA (Invitrogen) using Lipofectamine2000 (Invitrogen) and siRNA sequences as described above. Two days after transfection, cells were washed twice with PBS and then incubated in methionine-free DMEM (BMS) medium for $1 \mathrm{~h}$. Cells were then incubated for $20 \mathrm{~min}$ after supplementation with $\left[{ }^{35} \mathrm{~S}\right]$-methionine $\left(\left[{ }^{35} \mathrm{~S}\right]-\mathrm{Met}\right.$; $500 \mu \mathrm{Ci} / \mathrm{mL}$; Perkin-Elmer Life Science Products), washed twice with ice-cold PBS, harvested, and lysed. Protein concentration of cell extracts was measured using Bradford assay. For the quantitation of $\left[{ }^{35} \mathrm{~S}\right]$ Met-labeled proteins, $25 \mu \mathrm{g}$ of cell extracts were subjected to $10 \%$ SDS-PAGE and analyzed by autoradiography. Alternatively, the newly synthesized, $\left[{ }^{35} \mathrm{~S}\right]$-Met-labeled proteins were precipitated in $10 \%$ TCA $(\mathrm{w} / \mathrm{v})$. The precipitated proteins were dis- solved in water and then subjected to liquid scintillation analysis (Packard).

\section{Immunopurification-coupled in vitro translation}

Cos-7 cells were transfected with pRL-CMV, which expresses RLuc, and Flag tag-expressing plasmid: pcDNA3-Flag, pcDNA3Flag-CBP80, or pcDNA3-Flag-eIF4E. Two days after transfection, immunopurification was performed with cell extracts using $\alpha$-Flag antibody. After immunopurification, resin-bound RNP complex was eluted with $3 \times$ Flag peptides (Sigma).

In vitro translation reactions were performed for $15 \mathrm{~min}$ at $30^{\circ} \mathrm{C}$ in $38-\mu \mathrm{L}$ reaction mixtures containing $4 \mu \mathrm{L}$ of immunopurified CBP80-RNP or eIF4E-RNP complex that was eluted using Flag peptides, and $1 \mu \mathrm{g}$ of recombinant 6xHis-CTIF. To measure the activity of the newly translated luciferase during in vitro translation, a basal level of luciferase activity was first measured right after addition of immunopurified CBP80-RNP or eIF4E-RNP complex to in vitro translation mixture. And the level of translated luciferase was measured after incubation. The level of the newly synthesized luciferase was calculated by subtracting the basal level measured before incubation from the level of luciferase measured after incubation. The absolute values of basal levels in our conditions were $\sim 100$. Luciferase activity was measured by Luciferase assay kit (Promega) according to the manufacturer's instructions.

\section{siRNA-mediated down-regulation of CTIF and eIF4GI/II}

HeLa cells were grown in DMEM medium (Lonza) containing $10 \%$ fetal bovine serum (Lonza). Transient transfections were performed as described previously (YK Kim et al. 2005; Cho et al. 2009). In brief, cells were transfected with $100 \mathrm{nM}$ in vitrosynthesized siRNA (Invitrogen) using Oligofectamine (Invitrogen). Control siRNA and Upf1 siRNA sequences were reported previously (YK Kim et al. 2005). Cellular CTIF, eIF4GI, and eIF4GII were down-regulated using 5'-r|GCAUCAACCUGAAU GACAU)d(TT)-3' , 5' -r(UGAGAAAGGAGGAGAGGAA)d(TT)-3', and $5^{\prime}$-r(CCACGCCUGUAGAGUUUGA)d(TT)-3', respectively.

\section{Semiquantitative RT-PCR}

Semiquantitative RT-PCR were carried out using specific oligonucleotides and $\alpha-\left[{ }^{32} \mathrm{P}\right]$-dATP (PerkinElmer NEN) as described previously (Ishigaki et al. 2001; YK Kim et al. 2005; Cho et al. 2009). Labeled PCR products were separated by gel electrophoresis and visualized by autoradiography.

Oligonucleotides used for amplification of $\beta$-Gl, GPx1, MUP, COMMD7, IARS, and GAPDH mRNAs were reported previously (Ishigaki et al. 2001; YK Kim et al. 2005; Cho et al. 2009).

$\beta$-Gl pre-mRNA was amplified using two oligonucleotides: 5'-GCCTATTGGTCTATTTTCCC-3' (sense) and 5' -CCTGAAG TTCTCAGGATC-3' (antisense). RLuc mRNAs and 28S rRNA were amplified using two specific oligonucleotides: $5^{\prime}$-CACTGG GCAGGTGTCCACTC-3' (sense) and 5'-GTTCTGGATCATAA ACTTTC-3' (antisense) for RLuc mRNA, and 5'-AAGCAGGAG GTGTCAGAAA-3' (sense) and 5'-GGATTCTGACTTAGAGGC GTTCAGT-3' (antisense) for 28S rRNA, respectively.

\section{Immunostaining}

Immunostaining was performed as described previously $/ \mathrm{Oh}$ et al. 2007a,b; Cho et al. 2009). In brief, HeLa or Cos-7 cells were fixed with $2 \%$ paraformaldehyde (Merck) in PBS for $10 \mathrm{~min}$ and permeabilized with $0.5 \%$ Triton X-100 in PBS for $10 \mathrm{~min}$. Cells were incubated with blocking buffer (1.5\% BSA in PBS) for 
$1 \mathrm{~h}$, and then with primary antibodies. The primary antibodies $(\alpha$-eIF4GI antibody, $\alpha$-CTIF antibody, $\alpha$-Flag antibody [Sigma], $\alpha$-Myc antibody [Santa Cruz Biotechnologies], and $\alpha$-Lamin A/C antibody [Santa Cruz Biotechnologies]) were detected with fluorescein- and rhodamine-conjugated secondary antibodies (Pierce). Nuclei were stained with DAPI (Biotium). Cells were then observed with a ZEISS confocal microscope (LSM510 META).

\section{Acknowledgments}

We thank L.E. Maquat for critical reading of the manuscript and for providing NMD reporter plasmids, $\alpha-U p f 1$ antibody, and $\alpha$-Upf3X antibody; R. Reed for $\alpha$-CBP80; J.W. Hershey for $\alpha$-eIF3 antibody; and N. Sonenberg for pcDNA3-HA-eIF4AIII. This work was supported by grant FPR05B 1-310 of the 21C Frontier Functional Proteomics Project from KMST and grant R17-2007-089-01001-0 of NRL from KOSEF to S.K.J, and the Korea Research Foundation Grant funded by the Korean Government (MOEHRD) (KRF-2007-313-C00512) and the Basic Science Research Program through the National Research Foundation of Korea (NRF) funded by the Ministry of Education, Science and Technology (2009-0078061) to Y.K.K. H.C. and K.M.K. were supported in part by a Seoul Science Fellowship.

\section{References}

Alvarez E, Castello A, Menendez-Arias L, Carrasco L. 2006. HIV protease cleaves poly(A)-binding protein. Biochem $I$ 396: 219-226.

Baron-Benhamou J, Fortes $\mathrm{P}$, Inada $\mathrm{T}$, Preiss $\mathrm{T}$, Hentze MW. 2003. The interaction of the cap-binding complex (CBC) with eIF4G is dispensable for translation in yeast. RNA 9: 654662.

Behm-Ansmant I, Gatfield D, Rehwinkel J, Hilgers V, Izaurralde E. 2007a. A conserved role for cytoplasmic poly(A)-binding protein 1 (PABPC1) in nonsense-mediated mRNA decay. EMBO / 26: 1591-1601.

Behm-Ansmant I, Kashima I, Rehwinkel J, Sauliere J, Wittkopp N, Izaurralde E. 2007b. mRNA quality control: An ancient machinery recognizes and degrades mRNAs with nonsense codons. FEBS Lett 581: 2845-2853.

Belgrader P, Cheng J, Zhou X, Stephenson LS, Maquat LE. 1994. Mammalian nonsense codons can be cis effectors of nuclear mRNA half-life. Mol Cell Biol 14: 8219-8228.

Chang YF, Imam JS, Wilkinson MF. 2007. The nonsense-mediated decay RNA surveillance pathway. Annu Rev Biochem 76: 51-74.

Chiu SY, Lejeune F, Ranganathan AC, Maquat LE. 2004. The pioneer translation initiation complex is functionally distinct from but structurally overlaps with the steadystate translation initiation complex. Genes \& Dev 18: 745754.

Cho H, Kim KM, Kim YK. 2009. Human proline-rich nuclear receptor coregulatory protein 2 mediates an interaction between mRNA surveillance machinery and decapping complex. Mol Cell 33: 75-86.

Eberle AB, Lykke-Andersen S, Muhlemann O, Jensen TH. 2009. SMG6 promotes endonucleolytic cleavage of nonsense mRNA in human cells. Nat Struct Mol Biol 16: 49-55.

Etchison D, Milburn SC, Edery I, Sonenberg N, Hershey JW. 1982. Inhibition of HeLa cell protein synthesis following poliovirus infection correlates with the proteolysis of a 220,000-dalton polypeptide associated with eucaryotic initiation factor 3 and a cap binding protein complex. I Biol Chem 257: 14806-14810.
Fukuhara N, Ebert J, Unterholzner L, Lindner D, Izaurralde E, Conti E. 2005. SMG7 is a 14-3-3-like adaptor in the nonsensemediated mRNA decay pathway. Mol Cell 17: 537-547.

Hinnebusch AG. 2006. eIF3: A versatile scaffold for translation initiation complexes. Trends Biochem Sci 31: 553-562.

Hosoda N, Kim YK, Lejeune F, Maquat LE. 2005. CBP80 promotes interaction of Upf1 with Upf2 during nonsensemediated mRNA decay in mammalian cells. Nat Struct Mol Biol 12: 893-901.

Huntzinger E, Kashima I, Fauser M, Sauliere J, Izaurralde E. 2008. SMG6 is the catalytic endonuclease that cleaves mRNAs containing nonsense codons in metazoan. RNA 14: 2609-2617.

Ishigaki Y, Li X, Serin G, Maquat LE. 2001. Evidence for a pioneer round of mRNA translation: mRNAs subject to nonsense-mediated decay in mammalian cells are bound by CBP80 and CBP20. Cell 106: 607-617.

Isken O, Maquat LE. 2007. Quality control of eukaryotic mRNA: Safeguarding cells from abnormal mRNA function. Genes \& Dev 21: 1833-1856.

Joachims M, Van Breugel PC, Lloyd RE. 1999. Cleavage of poly(A)-binding protein by enterovirus proteases concurrent with inhibition of translation in vitro. J Virol 73: 718-727.

Kashima I, Yamashita A, Izumi N, Kataoka N, Morishita R, Hoshino S, Ohno M, Dreyfuss G, Ohno S. 2006. Binding of a novel SMG-1-Upf1-eRF1-eRF3 complex (SURF) to the exon junction complex triggers Upf1 phosphorylation and nonsense-mediated mRNA decay. Genes \& Dev 20: 355-367.

Kim WJ, Back SH, Kim V, Ryu I, Jang SK. 2005. Sequestration of TRAF2 into stress granules interrupts tumor necrosis factor signaling under stress conditions. Mol Cell Biol 25: 24502462.

Kim YK, Furic L, Desgroseillers L, Maquat LE. 2005. Mammalian Staufen1 recruits Upf1 to specific mRNA 3'UTRs so as to elicit mRNA decay. Cell 120: 195-208.

Lejeune F, Ishigaki Y, Li X, Maquat LE. 2002. The exon junction complex is detected on CBP80-bound but not eIF4E-bound mRNA in mammalian cells: Dynamics of mRNP remodeling. $E M B O$ J 21: 3536-3545.

Lejeune F, Ranganathan AC, Maquat LE. 2004. eIF4G is required for the pioneer round of translation in mammalian cells. Nat Struct Mol Biol 11: 992-1000.

Li Q, Imataka H, Morino S, Rogers GW Jr, Richter-Cook NJ, Merrick WC, Sonenberg N. 1999. Eukaryotic translation initiation factor 4AIII (eIF4AIII) is functionally distinct from eIF4AI and eIF4AII. Mol Cell Biol 19: 7336-7346.

Lykke-Andersen J, Shu MD, Steitz JA. 2000. Human Upf proteins target an mRNA for nonsense-mediated decay when bound downstream of a termination codon. Cell 103: 11211131.

Ma XM, Yoon SO, Richardson CJ, Julich K, Blenis J. 2008. SKAR links pre-mRNA splicing to mTOR/S6K1-mediated enhanced translation efficiency of spliced mRNAs. Cell 133: 303-313.

Mangus DA, Evans MC, Jacobson A. 2003. Poly(A)-binding proteins: Multifunctional scaffolds for the post-transcriptional control of gene expression. Genome Biol 4: 223. doi: 10.1186-2003-4-7-223.

Maquat LE. 2005. Nonsense-mediated mRNA decay in mammals. J Cell Sci 118: 1773-1776.

Maquat LE, Li X. 2001. Mammalian heat shock p70 and histone $\mathrm{H} 4$ transcripts, which derive from naturally intronless genes, are immune to nonsense-mediated decay. RNA 7: 445-456.

Marin-Vinader L, van Genesen ST, Lubsen NH. 2006. mRNA made during heat shock enters the first round of translation. Biochim Biophys Acta 1759: 535-542. 
Mattout A, Dechat T, Adam SA, Goldman RD, Gruenbaum Y. 2006. Nuclear lamins, diseases and aging. Curr Opin Cell Biol 18: 335-341.

McKendrick L, Thompson E, Ferreira J, Morley SJ, Lewis JD. 2001. Interaction of eukaryotic translation initiation factor 4G with the nuclear cap-binding complex provides a link between nuclear and cytoplasmic functions of the $\mathrm{m}(7)$ guanosine cap. Mol Cell Biol 21: 3632-3641.

Mendell JT, ap Rhys CM, Dietz HC. 2002. Separable roles for rent1/hUpf1 in altered splicing and decay of nonsense transcripts. Science 298: 419-422.

Mendell JT, Sharifi NA, Meyers JL, Martinez-Murillo F, Dietz HC. 2004. Nonsense surveillance regulates expression of diverse classes of mammalian transcripts and mutes genomic noise. Nat Genet 36: 1073-1078.

Moriarty PM, Reddy CC, Maquat LE. 1998. Selenium deficiency reduces the abundance of mRNA for Se-dependent glutathione peroxidase 1 by a UGA-dependent mechanism likely to be nonsense codon-mediated decay of cytoplasmic mRNA. Mol Cell Biol 18: 2932-2939.

Morris C, Wittmann J, Jack HM, Jalinot P. 2007. Human INT6/ eIF3e is required for nonsense-mediated mRNA decay. EMBO Rep 8: 596-602.

Neu-Yilik G, Kulozik AE. 2008. NMD: Multitasking between mRNA surveillance and modulation of gene expression. AdV Genet 62: 185-243.

Oh N, Kim KM, Cho H, Choe J, Kim YK. 2007a. Pioneer round of translation occurs during serum starvation. Biochem Biophys Res Commun 362: 145-151.

Oh N, Kim KM, Choe J, Kim YK. 2007b. Pioneer round of translation mediated by nuclear cap-binding proteins CBP80/ 20 occurs during prolonged hypoxia. FEBS Lett 581: 51585164.

Pestova TV, Lorsch JR, Hellen CU. 2007. The mechanism of translation initiation in eukaryotes. In Translational control in biology and medicine (eds. MB Mathews et al.), pp. 87-128. Cold Spring Harbor Laboratory Press, Cold Spring Harbor, NY.

Rebbapragada I, Lykke-Andersen J. 2009. Execution of nonsensemediated mRNA decay: What defines a substrate? Curr Opin Cell Biol 21: 394-402.

Rehwinkel J, Raes J, Izaurralde E. 2006. Nonsense-mediated mRNA decay: Target genes and functional diversification of effectors. Trends Biochem Sci 31: 639-646.

Rousseau D, Kaspar R, Rosenwald I, Gehrke L, Sonenberg N. 1996. Translation initiation of ornithine decarboxylase and nucleocytoplasmic transport of cyclin D1 mRNA are increased in cells overexpressing eukaryotic initiation factor 4E. Proc Natl Acad Sci 93: 1065-1070.

Sato H, Hosoda N, Maquat LE. 2008. Efficiency of the pioneer round of translation affects the cellular site of nonsensemediated mRNA decay. Mol Cell 29: 255-262.

Sun X, Perlick HA, Dietz HC, Maquat LE. 1998. A mutated human homologue to yeast Upf1 protein has a dominantnegative effect on the decay of nonsense-containing mRNAs in mammalian cells. Proc Natl Acad Sci 95: 10009-10014.

Unterholzner L, Izaurralde E. 2004. SMG7 acts as a molecular link between mRNA surveillance and mRNA decay. Mol Cell 16: 587-596.

Viegas $\mathrm{MH}$, Gehring NH, Breit S, Hentze MW, Kulozik AE. 2007. The abundance of RNPS1, a protein component of the exon junction complex, can determine the variability in efficiency of the nonsense mediated decay pathway. Nucleic Acids Res 35: 4542-4551.

Wittmann J, Hol EM, Jack HM. 2006. hUPF2 silencing identifies physiologic substrates of mammalian nonsense-mediated mRNA decay. Mol Cell Biol 26: 1272-1287.
Yamashita A, Kashima I, Ohno S. 2005. The role of SMG-1 in nonsense-mediated mRNA decay. Biochim Biophys Acta 1754: 305-315.

Yamashita A, Izumi N, Kashima I, Ohnishi T, Saari B, Katsuhata Y, Muramatsu R, Morita T, Iwamatsu A, Hachiya T, et al. 2009. SMG-8 and SMG-9, two novel subunits of the SMG-1 complex, regulate remodeling of the mRNA surveillance complex during nonsense-mediated mRNA decay. Genes \& Dev 23: 1091-1105.

You KT, Li LS, Kim NG, Kang HJ, Koh KH, Chwae YJ, Kim KM, Kim YK, Park SM, Jang SK, et al. 2007. Selective translational repression of truncated proteins from frameshift mutation-derived mRNAs in tumors. PLOS Biol 5: e109. doi: 10.1371/journal.pbio.0050109.

Zhang J, Sun X, Qian Y, Maquat LE. 1998. Intron function in the nonsense-mediated decay of $\beta$-globin mRNA: Indications that pre-mRNA splicing in the nucleus can influence mRNA translation in the cytoplasm. RNA 4: 801-815. 


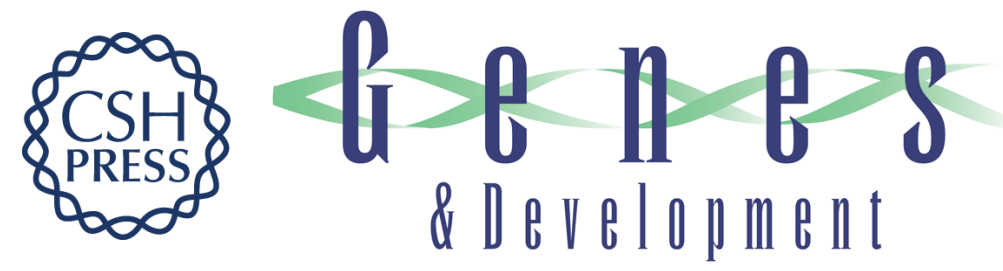

\title{
A new MIF4G domain-containing protein, CTIF, directs nuclear cap-binding protein CBP80/20-dependent translation
}

\author{
Kyoung Mi Kim, Hana Cho, Kobong Choi, et al.
}

Genes Dev. 2009, 23: originally published online July 31, 2009

Access the most recent version at doi:10.1101/gad.1823409

\section{Supplemental http://genesdev.cshlp.org/content/suppl/2009/08/03/gad.1823409.DC1 Material}

References This article cites 50 articles, 22 of which can be accessed free at: http://genesdev.cshlp.org/content/23/17/2033.full.html\#ref-list-1

\section{License}

Email Alerting

Service

Receive free email alerts when new articles cite this article - sign up in the box at the top right corner of the article or click here.

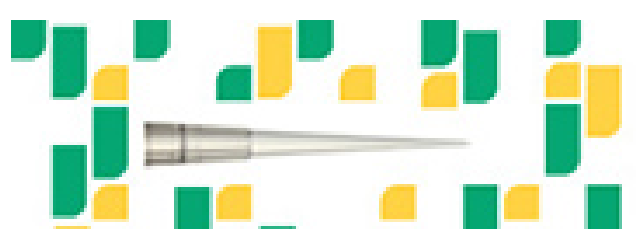

Focused on your science. 